\title{
Perception of pain in the minimally conscious state with PET activation: an observational study
}

Mélanie Boly, Marie-Elisabeth Faymonville, Caroline Schnakers, Philippe Peigneux, Bernard Lambermont, Christophe Phillips, Patrizio Lancellotti, Andre Luxen, Maurice Lamy, Gustave Moonen, Pierre Maquet, Steven Laureys

\section{Summary}

Background Patients in a minimally conscious state (MCS) show restricted self or environment awareness but are unable to communicate consistently and reliably. Therefore, better understanding of cerebral noxious processing in these patients is of clinical, therapeutic, and ethical relevance.

Methods We studied brain activation induced by bilateral electrical stimulation of the median nerve in five patients in MCS (aged 18-74 years) compared with 15 controls (19-64 years) and 15 patients (19-75 years) in a persistent vegetative state (PVS) with ${ }^{15} \mathrm{O}$-radiolabelled water PET. By way of psychophysiological interaction analysis, we also investigated the functional connectivity of the primary somatosensory cortex (S1) in patients and controls. Patients in MCS were scanned 57 (SD 33) days after admission, and patients in PVS 36 (9) days after admission. Stimulation intensities were 8.6 (SD 6.7) $\mathrm{mA}$ in patients in MCS, $7.4(5.9) \mathrm{mA}$ in controls, and $14 \cdot 2(8 \cdot 7) \mathrm{mA}$ in patients in PVS. Significant results were thresholded at $p$ values of less than 0.05 and corrected for multiple comparisons.

Findings In patients in MCS and in controls, noxious stimulation activated the thalamus, S1, and the secondary somatosensory or insular, frontoparietal, and anterior cingulate cortices (known as the pain matrix). No area was less activated in the patients in MCS than in the controls. All areas of the cortical pain matrix showed greater activation in patients in MCS than in those in PVS. Finally, in contrast with patients in PVS, those in MCS had preserved functional connectivity between $\mathrm{S} 1$ and a widespread cortical network that includes the frontoparietal associative cortices.

Interpretation Cerebral correlates of pain processing are found in a similar network in controls and patients in MCS but are much more widespread than in patients in PVS. These findings might be objective evidence of a potential pain perception capacity in patients in MCS, which supports the idea that these patients need analgesic treatment.

Funding FNRS; Reine Elisabeth Medical Foundation; University of Liège; European Commission; James S McDonnell Foundation; Mind Science Foundation; Concerted Research Action; Fondation Léon Frédéricq.

\section{Introduction}

A persistent vegetative state (PVS) is defined by wakefulness without awareness of self or the environment, ${ }^{1}$ whereas patients in a minimally conscious state (MCS) show some evidence of self and environmental awareness. ${ }^{2}$ However, the carers of patients who are minimally conscious have difficulties in assessing the patients' level of conscious pain perception through their behaviour. Moreover, there are no guidelines on pain treatment in patients in MCS. ${ }^{3}$ Noxious stimulation is a routine clinical procedure for the bedside assessment of consciousness in patients who are severely brain damaged. Noxious stimulation is also part of the commonly used coma scales, such as the Glasgow coma scale (GCS), ${ }^{4}$ the reaction level scale, ${ }^{5}$ the Innsbruck coma scale, ${ }^{6}$ the Edinburgh 2 coma scale, and the coma recovery scale. ${ }^{8}$ The study of cerebral processing of noxious stimulation in these patients is also of clinical, therapeutic, and ethical relevance. ${ }^{9}$ We have previously reported on the cortical responses of patients in PVS to similar noxious somatosensory stimuli by use of ${ }^{15} \mathrm{O}$-radiolabelled water PET, ${ }^{10}$ and found that the only areas that significantly responded to noxious stimulation in patients in PVS were the brainstem, contralateral thalamus, and primary somatosensory cortex (S1). Here, we used an identical set-up to study five patients who are in MCS and compared the results with those from patients in PVS and 15 healthy controls.

\section{Methods}

Participants

Five non-sedated patients in MCS (4 men; mean age 49 [SD 22] years, range 18-74 years), 15 non-sedated patients in PVS (12 men; mean age 48 [17] years, range 19-75 years), and 15 healthy volunteers ( 8 male; mean age 40 [9] years, range 19-64 years) were studied prospectively. Table 1 shows the demographic data of the patients in MCS. The aetiologies of the patients in PVS were: cardiorespiratory arrest $(n=5)$, diffuse axonal injury $(\mathrm{n}=3)$, drugs overdose $(\mathrm{n}=2)$, prolonged respiratory insufficiency $(n=2)$, encephalitis with diffuse white matter lesions $(n=2)$, and carbon monoxide intoxication $(n=1)$. Clinical diagnoses were made on the basis of repeated, standardised evaluation ${ }^{11}$ and conformed to international criteria for PVS ${ }^{12}$ and MCS. ${ }^{13}$ Patients were assessed four times by trained and experienced assessors (SL and CS): 1 week and 1 day before scanning, the day of
Lancet Neurol 2008; 7: 1013-20 Published Online October 6, 2008 DOI:10.1016/S14744422(08)70219-9

See Reflection and Reaction page 979

Coma Science Group Cyclotron Research Center (M Boly MD, C Schnakers PhD, A Luxen PhD, C Phillips PhD, P Maquet MD, S Laureys MD), Department of Neurology (M Boly, G Moonen MD, P Maquet, S Laureys), Department of Anesthesiology and Reanimation (M-E Faymonville MD, M Lamy MD), and Department of Internal Medicine (B Lambermont MD, P Lancellotti MD), University of Liège, Belgium; and UR2NF, Université Libre de Bruxelles, Belgium (P Peigneux PhD)

Correspondence to:

Steven Laureys, Coma Science Group, Cyclotron Research Center and Department of Neurology, University of Liège, Sart Tilman B30, 4000 Liège, Belgium steven.laureys@ulg.ac.be 
the scan, and 1 week after the scan. None of the patients in MCS showed localisation in response to noxious stimuli and none of the patients in PVS showed normal flexion or withdrawal in response to noxious stimuli. Mean $\mathrm{GCS}^{4}$ on admission were 6 (SD 5) points for the patients who were minimally conscious and 5 (3) points for the patients in PVS. All patients had preserved pupillary, corneal, and vestibulo-ocular reflexes. Assessment of median nerve sensory conduction velocity and somatosensory evoked potential excluded peripheral nerve, plexus, or spinal cord lesions. Short latency auditory evoked potentials showed preserved pontine and midbrain functions in all patients.

\section{Procedures}

Patients in MCS were scanned a mean of 57 (SD 33) days after admission and patients in PVS 36 (9) days after admission. Patients were scanned during awake periods, as shown by simultaneous polygraphic recordings (electroencephalogram and electro-oculogram). Throughout the procedure, patients were monitored by a senior anaesthetist (MEF), assisted by an intensive care physician. Written, informed consent was obtained from the people with legal responsibility for the patients and from all controls personally. Stimulation was kept at the minimum duration $(6 \times 70 \mathrm{~s})$ and minimum intensity needed for PET. Stimulation intensities were increased to the point where all components of the somatosensory evoked potentials showed maximum amplitude ${ }^{14}$ the stimulation intensity was then kept constant throughout the experiment. Electrical stimulation of the median nerve at the intensity used was rated as highly unpleasant to painful by the controls..$^{10}$ Stimulation intensity was not significantly different for the patients in MCS than for patients in PVS or controls (MCS mean 8.6 [SD 6.7] mA; PVS mean 14.2 [8.7] mA; controls mean $7 \cdot 4$ [5.9] $\mathrm{mA}$ ).

\begin{tabular}{|c|c|c|c|c|c|}
\hline & Patient 1 & Patient 2 & Patient $3^{*}$ & Patient 4 & Patient $5^{*}$ \\
\hline Sex & Male & Female & Male & Male & Male \\
\hline Age (years) & 41 & 64 & 74 & 18 & 50 \\
\hline Cause & Cardiorespiratory arrest & $\begin{array}{l}\text { Respiratory arrest and } \\
\text { hypotension }\end{array}$ & Encephalitis & $\begin{array}{l}\text { Traumatic posterior fossa } \\
\text { haematoma }\end{array}$ & Diffuse axonal injury \\
\hline Glasgow coma score on admission & 3 points & 3 points & 14 points & 6 points & 6 points \\
\hline Time from admission to PET & 41 days & 116 days & 40 days & 50 days & 37 days \\
\hline Outcome at 12 months & Distinctly dependent & Distinctly dependent & Died & Moderately dependent & Distinctly dependent \\
\hline \multicolumn{6}{|l|}{ Clinical evaluation at time of PET } \\
\hline Interactive communication & Absent & Absent & Absent & Absent & Absent \\
\hline Functional use of $\geq 2$ objects & Absent & Absent & Absent & Absent & Absent \\
\hline Best verbal response & None & Incomprehensible sounds & None & None & Incomprehensible sounds \\
\hline Best gestural response & $\begin{array}{l}\text { Smiles in response to } \\
\text { relevant visual stimuli }\end{array}$ & $\begin{array}{l}\text { Inconsistent tongue protrusion } \\
\text { to auditory command }\end{array}$ & $\begin{array}{l}\text { Smiles in response to } \\
\text { relevant verbal stimuli }\end{array}$ & $\begin{array}{l}\text { Inconsistent movement of left } \\
\text { foot to auditory command }\end{array}$ & Tongue protrusion \\
\hline $\begin{array}{l}\text { Best motor response to } \\
\text { noxious stimuli }\end{array}$ & Flexion withdrawal & $\begin{array}{l}\text { Stereotyped extension } \\
\text { posturing }\end{array}$ & $\begin{array}{l}\text { Stereotyped flexion } \\
\text { posturing }\end{array}$ & Flexion withdrawal & $\begin{array}{l}\text { Stereotyped extension } \\
\text { posturing }\end{array}$ \\
\hline Eye opening & Spontaneous & Spontaneous & Spontaneous & Spontaneous & Spontaneous \\
\hline Sleep-wake cycles & Present & Present & Present & Present & Present \\
\hline Arousal level & Fluctuates & Healthy & Healthy & Fluctuates & Fluctuates \\
\hline Eye movements & Fixation on family members & Tracking & $\begin{array}{l}\text { Tracking of family } \\
\text { members }\end{array}$ & Tracking & $\begin{array}{l}\text { Inconsistent tracking and } \\
\text { fixation }\end{array}$ \\
\hline Eye blinking to visual threat & Present & Present & Present & Present & Present \\
\hline Breathing & Healthy & Healthy & Healthy & Healthy & Healthy \\
\hline Gag reflex & Present & Present & Present & Present & Present \\
\hline Deep tendon reflexes & Raised & Raised & Raised & Raised & Raised \\
\hline Skeletal muscle tone & Spastic & Spastic & Spastic & Spastic & Spastic \\
\hline Paralysis or paresis & Bilateral & Bilateral & Bilateral & Bilateral & Bilateral \\
\hline Babinski's sign & Bilateral & Absent & Absent & Bilateral & Absent \\
\hline \multicolumn{6}{|l|}{ EEG } \\
\hline Background activity & Disorganised delta waves & $\begin{array}{l}\text { Reactive and disorganised } \\
\text { theta waves }\end{array}$ & Disorganised theta waves & $\begin{array}{l}\text { Reactive and disorganised } \\
\text { theta waves }\end{array}$ & Disorganised delta waves \\
\hline \multicolumn{6}{|l|}{ MRI } \\
\hline $\begin{array}{l}\text { Increased intensity on } \\
\text { T2-weighted MRI }\end{array}$ & Periventricular & $\begin{array}{l}\text { Diffuse white matter and } \\
\text { cortical atrophy }\end{array}$ & Diffuse white matter & $\begin{array}{l}\text { Intracerebellar, left occipital, } \\
\text { and bifrontal contusions }\end{array}$ & Diffuse white matter \\
\hline${ }^{*}$ Previously reported. ${ }^{1}$ & & & & & \\
\hline
\end{tabular}


The stimulation intensities used in non-communicative patients were lower than those used routinely when somatosensory evoked potentials are recorded at an intensive care unit. ${ }^{15}$

The study was approved by the ethics committee of the Faculty of Medicine of the University of Liège and done in accordance with the Declaration of Helsinki ${ }^{16}$ and the International Association for the Study of Pain (IASP) Ethical Guidelines for Pain Research in Humans. ${ }^{17}$

Changes in regional cerebral blood flow were measured with ${ }^{15} \mathrm{O}$-radiolabelled water PET, as described elsewhere. ${ }^{10}$ Data acquisition in patients in MCS started
24 months after the study in patients in PVS. ${ }^{10}$ Scans were done during rest and electrical stimulation of the left-sided and right-sided median nerve $(0.2 \mathrm{~ms}$ squarewave pulses at $5 \cdot 1 \mathrm{~Hz}$ at the wrist). We chose bilateral median nerve stimulation because this meant that both hemispheres were recruited in patients with severe brain injury. The conditions of each test were repeated three times (except in one patient, in whom only two scans could be obtained for left-sided and two scans for right-sided noxious stimulation). The order or presentation was pseudorandomised for all patients. Haemodynamic parameters were monitored, and

\begin{tabular}{|c|c|c|c|c|c|c|c|}
\hline & Region (Brodmann area) & Side & $x$ & $y$ & z & $z$ value & Corrected $\mathrm{p}$ value \\
\hline \multicolumn{8}{|l|}{ Controls } \\
\hline \multirow[t]{16}{*}{ Activations } & \multirow[t]{2}{*}{ Thalamus } & Contralateral & -10 & -10 & 8 & $4 \cdot 50$ & 0.0001 \\
\hline & & Ipsilateral & 6 & -6 & 8 & 3.85 & 0.001 \\
\hline & Primary somatosensory cortex & Contralateral & -48 & -28 & 58 & $5 \cdot 42$ & $<0.0001$ \\
\hline & Secondary sensory cortex/insula & Contralateral & -38 & -22 & 12 & $7 \cdot 42$ & $<0.0001$ \\
\hline & \multirow[t]{2}{*}{ Inferior parietal lobule (39/40) } & Contralateral & -64 & -34 & 36 & $4 \cdot 70$ & $<0.0001$ \\
\hline & & Ipsilateral & 66 & -42 & 34 & $3 \cdot 34$ & 0.007 \\
\hline & \multirow[t]{2}{*}{ Inferior parietal lobule (7/40) } & Contralateral & -50 & -66 & 44 & $2 \cdot 82$ & 0.023 \\
\hline & & Ipsilateral & 48 & -66 & 46 & 2.90 & 0.020 \\
\hline & \multirow[t]{2}{*}{ Superior temporal gyrus (22/42) } & Contralateral & -62 & -34 & 20 & 5.97 & $<0.0001$ \\
\hline & & Ipsilateral & 66 & -34 & 24 & $4 \cdot 19$ & 0.0004 \\
\hline & \multirow{2}{*}{ Striatum } & Contralateral & -26 & -10 & 0 & 5.04 & $<0.0001$ \\
\hline & & Ipsilateral & 22 & 16 & 2 & $4 \cdot 28$ & 0.0003 \\
\hline & Anterior cingulate cortex (24/32) & Medial & 2 & 20 & 36 & $5 \cdot 10$ & $<0.0001$ \\
\hline & Posterior cingulate cortex (23) & Medial & -4 & -20 & 32 & 4.76 & $<0.0001$ \\
\hline & \multirow[t]{2}{*}{$\operatorname{DLPFC}(9 / 10)$} & Contralateral & -32 & 52 & 26 & $3 \cdot 16$ & $0 \cdot 010$ \\
\hline & & Ipsilateral & 44 & 50 & -6 & $2 \cdot 60$ & 0.039 \\
\hline \multirow[t]{4}{*}{ Deactivations } & Posterior cingulate or precuneus & Medial & 10 & -54 & 62 & $3 \cdot 58$ & 0.002 \\
\hline & Medial prefrontal cortex & Medial & -2 & 52 & 26 & $2 \cdot 77$ & $0 \cdot 019$ \\
\hline & Parietal cortex & Ipsilateral & 24 & -36 & 54 & $4 \cdot 61$ & $<0.0001$ \\
\hline & Occipital cortex & Ipsilateral & 6 & -76 & 8 & $6 \cdot 17$ & $<0.0001$ \\
\hline \multicolumn{8}{|c|}{ Patients in MCS } \\
\hline \multirow[t]{8}{*}{ Activations } & Thalamus & Contralateral & -14 & -10 & 14 & $3 \cdot 27$ & $0.019^{*}$ \\
\hline & Primary somatosensory cortex & Contralateral & -46 & -26 & 54 & $4 \cdot 40$ & 0.008 \\
\hline & Secondary sensory cortex or insula & Contralateral & -34 & -24 & 26 & 4.93 & 0.007 \\
\hline & Inferior parietal lobule (39/40) & Contralateral & -64 & -38 & 28 & $3 \cdot 14$ & $0.016^{*}$ \\
\hline & Inferior parietal lobule (7/40) & Contralateral & -36 & -32 & 44 & $4 \cdot 75$ & 0.007 \\
\hline & Superior temporal gyrus (22/42) & Contralateral & -66 & -42 & 20 & $3 \cdot 16$ & $0.016^{*}$ \\
\hline & Anterior cingulate cortex (24/32) & Medial & 12 & 10 & 36 & $3 \cdot 21$ & $0.038^{*}$ \\
\hline & $\operatorname{DLPFC}(9 / 10)$ & Contralateral & -38 & 48 & 30 & $3 \cdot 48$ & $0.045^{*}$ \\
\hline \multirow[t]{2}{*}{ Deactivations } & Posterior cingulate or precuneus & Medial & -6 & -56 & 20 & 3.07 & $0.001 \dagger$ \\
\hline & Medial prefrontal cortex & Medial & 0 & 50 & -18 & 2.67 & $0.004^{*}$ \\
\hline \multicolumn{8}{|c|}{ Differences in stimulation-induced regional cerebral blood flow changes } \\
\hline Activations & No areas identified & & & & & & \\
\hline \multirow[t]{2}{*}{ Deactivations } & Posterior cingulate or precuneus & Medial & 2 & -54 & 62 & $4 \cdot 21$ & 0.009 \\
\hline & Occipital cortex & Contralateral & -18 & -78 & 18 & $4 \cdot 42$ & 0.009 \\
\hline $\begin{array}{l}\text { * Results are thres } \\
\text { coordinates from } \\
\text { cortex. }\end{array}$ & Ided at $\mathrm{p}$ values $<0.05$ corrected for $\mathrm{m}$ & e comparisons $\mathrm{V}$ & & & & ius sphere & $\begin{array}{l}\text { redetermined } \\
\text { orsolateral prefrontal }\end{array}$ \\
\hline
\end{tabular}



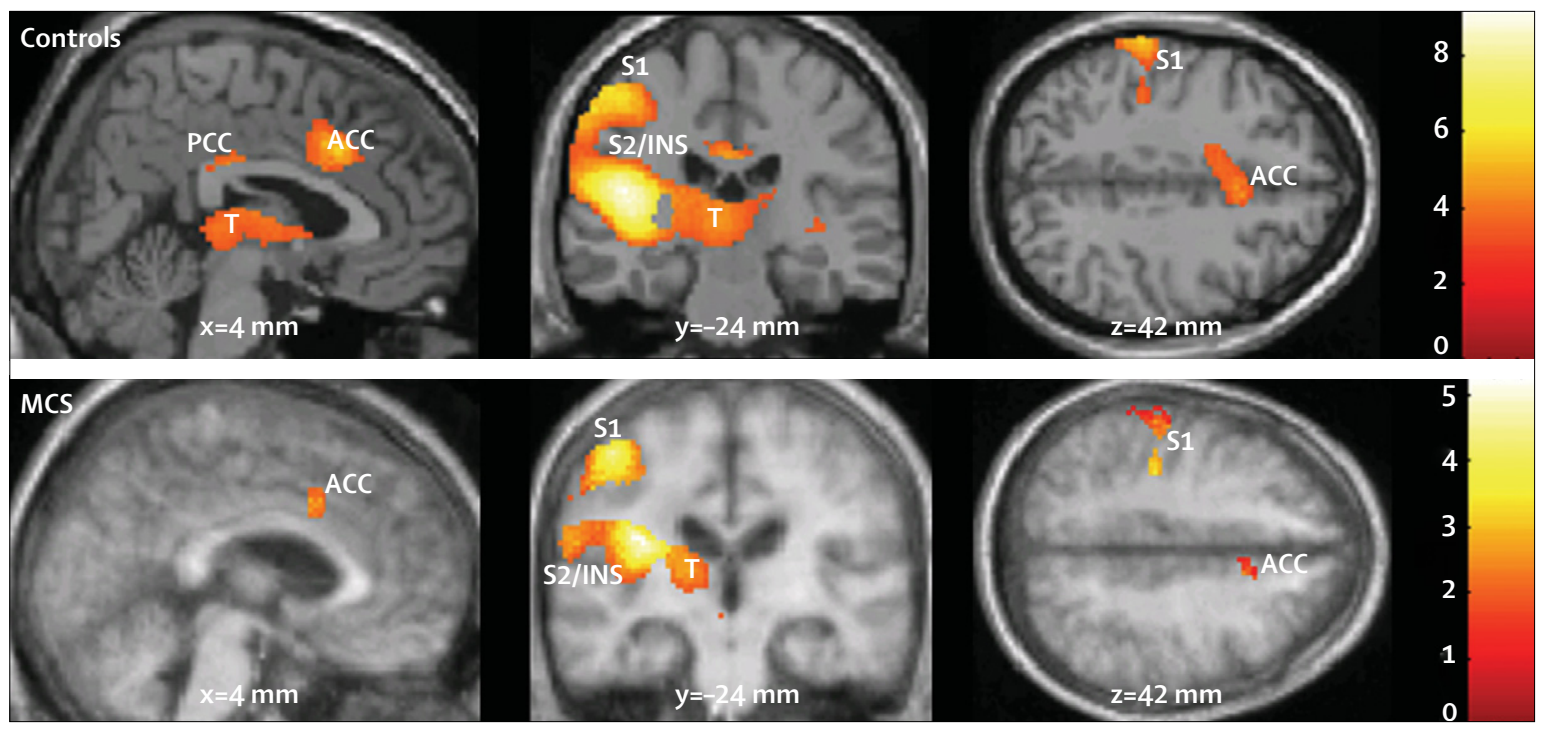

Figure: Brain activation to pain in controls and patients in MCS

(Top) Regions of the brain that were activated during noxious stimulation in controls (stimulation-rest). (Bottom) Brain regions commonly activated during stimulation in patients in MCS and in controls. Significant results were thresholded for display at uncorrected $p$ value $<0.001$ and projected on sagittal ( $x=4 \mathrm{~mm}$ ), coronal $(y=-24 \mathrm{~mm})$, and transverse $(z=42 \mathrm{~mm})$ sections of a normalised brain MRI template in controls and on the mean MRI of the patients (distances are relative to the bicommisural plane). $\mathrm{T}=$ thalamus. $\mathrm{PCC}=$ posterior cingulate cortex. $\mathrm{ACC}=$ anterior cingulate cortex. $\mathrm{S} 2 / \mathrm{INS}=$ secondary somatosensory cortex or insula. S1=primary somatosensory cortex.

electroencephalogram, electromyogram, ocular movements, and somatosensory evoked potentials were recorded throughout the procedure. A high-resolution, T1-weighted brain MRI was obtained for coregistration to the functional data.

\section{Statistical analysis}

PET data were realigned, spatially normalised, smoothed,

For more on statistical parametric mapping (SPM) see www.fil.ion.ucl.ac.uk/spm

and analysed with statistical parametric mapping. Because SPM is a more powerful voxel-based statistical method with more precise anatomical validity, it was preferred over the region-of-interest approach. A smoothing kernel of full width at a half maximum of $16 \mathrm{~mm}$ was chosen owing to the severely damaged brains of the patients in MCS or PVS. The smoothing was identical to that used in our previous study. ${ }^{10}$ Data obtained during left-sided noxious stimulation and at rest were flipped, as reported previously..$^{10} \mathrm{~A}$ random effects analysis ${ }^{18}$ identified the areas of the brain that were activated during noxious stimulation. We calculated one contrast between stimulation and rest per patient, which accounts for the within-patient component of the variance. We used these contrast images in a second design matrix that took into account the between-patient component of the variance and separated the data into three groups (controls, patients in PVS, and patients in MCS). The first two contrasts searched for brain activation in response to noxious stimulation in controls and patients in an MCS. We also looked for the group interaction ([controls-patients in MCS] $\times$ condition [stimulation-rest]) to search for areas that were less activated in patients in MCS than in healthy controls..$^{19} \mathrm{~A}$ second group interaction was done ([patients in MCS-patients in VS] $\times$ condition [stimulation-rest]) to search for the areas that were more activated in patients in MCS than patients in PVS. By use of reversed $T$ contrasts we also looked for and compared deactivations during noxious processing with baseline in controls and patients in MCS. The results from the patients were masked inclusively by the results from the controls (uncorrected $\mathrm{p}<0 \cdot 05$ ). The results from controls and comparisons between patient populations were thresholded at a whole-brain false discovery rate (FDR)corrected $\mathrm{p}$ value of less than $0 \cdot 05 .^{20,21}$ Results from patients in MCS were thresholded at $\mathrm{p}$ values less than 0.05 and corrected for multiple comparisons with FDR at the whole-brain level or in a small volume (spheres with $10 \mathrm{~mm}$ radii) centred on the peak voxels of interest that were identified in controls.

Finally, we did a psychophysiological analysis, as previously described. ${ }^{10}$ Our previous analysis was of the modulation between S1 and the rest of the brain in controls and patients. The first analysis looked for preserved modulation between S1 and the rest of the brain in patients in MCS compared with controls, by way of a conjunction approach-a conjunction analysis requires that all tested comparisons are individually significant. ${ }^{22}$ Here, we looked for brain regions that were significantly modulated by S1 in patients in MCS and controls. A second analysis looked for differences between patients in MCS and controls. Finally, we searched for differences of S1 functional connectivity between patients in MCS or patients in PVS. Results were masked inclusively by controls results (uncorrected 
$\mathrm{p}<0 \cdot 05)$. All results from psycho-physiological interactions were thresholded at a whole-brain FDRcorrected $\mathrm{p}$ value of less than $0 \cdot 05$.

\section{Role of the funding source}

The funding sources had no role in the study design, data collection, data analysis, data interpretation, or writing of this report. All authors had full access to all the data in the study and had final responsibility for the decision to submit for publication.

\section{Results}

In the controls, noxious stimulation resulted in the subjective experience of pain and increased regional cerebral blood flow in several areas, including the thalamus, striatum, contralateral S1, secondary somatosensory or insular cortices, superior temporal, posterior, parietal, posterior cingulate, prefrontal, and anterior cingulate cortices (table 2 and figure). Compared with baseline, deactivations could also be found in the posterior cingulate and precuneus and medial prefrontal cortices (table 2).

Patients who were minimally conscious also showed significant activation in all the areas activated in the controls (table 2, webfigure), although the pattern of activation was lateralised and with less spatial extent. The total extent of stimulus-induced cerebral activation (at an uncorrected $\mathrm{p}$ value of $<0.001$ ) in controls and patients in MCS was 4395 and 1471 voxels, respectively, taking into account the differences in the numbers of patients. However, the interaction analysis did not identify any voxel that was significantly less activated in the patients in MCS compared with controls. During noxious stimulation, the posterior cingulate or precuneus and medial prefrontal cortices also showed deactivation in patients in MCS, but there was no difference in deactivation after correction for multiple comparisons. However, deactivations in patients in MCS were significantly less pronounced than in controls (table 2).

Compared with patients in PVS, patients who were minimally conscious showed significantly greater activation in the S1, secondary somatosensory cortex or insula, anterior cingulate cortex, and posterior parietal and dorsolateral prefrontal cortices (table 3). No voxels were significantly less activated in patients in MCS compared with patients in PVS.

Finally, psychophysiological interaction analysis revealed preserved modulation between $\mathrm{S} 1$ and a large set of associative areas, including the high order frontoparietal cortices, in patients in MCS (table 4). Compared with controls, patients in MCS had impaired connectivity in the posterior cingulate or precuneus and in the medial prefrontal cortices. When patients in MCS were compared with patients in PVS, functional connectivity between the S1 and the lateral and medial frontoparietal areas was significantly higher in patients in MCS than those in PVS.

\begin{tabular}{|c|c|c|c|c|c|c|}
\hline & Side & $x$ & $y$ & $z$ & $z$ value & Corrected $\mathrm{p}$ value \\
\hline Primary somatosensory cortex & Contralateral & -36 & -28 & 34 & $4 \cdot 18$ & 0.019 \\
\hline Secondary sensory cortex/insula & Contralateral & -38 & -22 & 22 & $4 \cdot 14$ & 0.019 \\
\hline Inferior parietal lobule (39/40) & Contralateral & -44 & -32 & 32 & 4.00 & 0.023 \\
\hline Inferior parietal lobule (7/40) & Contralateral & -36 & -34 & 42 & 5.07 & 0.013 \\
\hline Superior temporal gyrus (41) & Contralateral & -42 & -30 & 6 & $3 \cdot 10$ & 0.046 \\
\hline Anterior cingulate cortex (24) & Medial & 12 & 8 & 40 & 3.02 & 0.050 \\
\hline DLPFC (9/10) & Contralateral & -38 & 46 & 32 & 3.66 & 0.030 \\
\hline \multicolumn{7}{|c|}{$\begin{array}{l}\text { All results are thresholded at a whole-brain FDR-corrected } p \text { value }<0.05 \text {. Figures in brackets are Brodmann areas. } \\
\text { DLPFC=dorsolateral prefrontal cortex. Data from patients in PVS has been published previously. }{ }^{10}\end{array}$} \\
\hline
\end{tabular}

\begin{tabular}{|llrrrrc|}
\hline & Side & $\mathbf{x}$ & $\mathbf{y}$ & $\mathbf{z}$ & $\mathbf{z}$ value & Corrected $\mathbf{p}$ value \\
\hline Patients in MCS and controls & & & & & & \\
Secondary sensory cortex/insula & Contralateral & -38 & -34 & 22 & 4.36 & 0.0001 \\
Posterior parietal cortex (40) & Contralateral & -62 & -16 & 22 & 6.07 & $<0.0001$ \\
Premotor cortex (6) & Contralateral & -56 & 2 & 34 & 4.98 & $<0.0001$ \\
DLPFC (9/10) & Contralateral & -40 & 52 & 20 & 3.34 & 0.004 \\
Superior temporal cortex (22) & Contralateral & -50 & -38 & 0 & 6.80 & $<0.0001$ \\
Patients in MCS<controls & & & & & & \\
Posterior cingulate or precuneus & Medial & 6 & -68 & 50 & 3.81 & 0.0003 \\
Medial prefrontal cortex & Medial & 6 & 66 & 20 & 3.74 & 0.0003 \\
Occipital cortex & Ipsilateral & 26 & -72 & 8 & Inf & $<0.0001$
\end{tabular}

All results are thresholded at whole-brain FDR-corrected $p$ value $<0.05$. Areas are significantly more connected to $S 1$ during noxious processing in patients in MCS compared with patients in PVS. Figures in brackets are Brodmann area. DLPFC=dorsolateral prefrontal cortex

Table 4: Areas that show preserved functional connectivity in patients in MCS and controls and in patients in MCS compared with patients in PVS

\section{Discussion}

Pain is a subjective experience. ${ }^{23}$ By definition, patients in See Online for webfigure MCS are unable to consistently and reliably communicate their experiences, and their behavioural responses to noxious stimulation are often difficult to interpret. Even if some patients in MCS can correctly answer yes or no questions at a level above chance, a question such as, "Are you in pain?" might not elicit a reliable response. The behavioural assessment of motor or autonomic signs (ie, respiratory frequency, heart rate, blood pressure, pupillary diameter, and skin conductance) are not reliable markers of the conscious perception of pain, as shown in studies done in general anaesthesia. ${ }^{24}$ The evaluation and treatment of pain is therefore an important clinical and ethical problem in patients in MCS. In this context, functional neuroimaging can objectively measure changes in brain function during noxious stimulation in these patients. Indeed, several authors have stressed the need for brain imaging studies of pain processing in patients who are in altered states of consciousness. ${ }^{12,25-27}$ The study of cerebral responses to painful stimuli in patients with altered states of consciousness can also help to understand pain processing in healthy patients. ${ }^{28}$ 
The role of different areas of the brain in pain processing is only partially understood, and the neural representation of the brain is thought to be both specific and integrated. In summary, the sensory-discriminative component of pain is thought to depend on primary and secondary somatosensory cortices, and the affectivemotivational on the anterior cingulate cortex and prefrontal areas-the insular cortex has an intermediate role. ${ }^{29-32}$

In healthy volunteers, electrical stimulation of the median nerve was perceived as highly unpleasant to painful and activated areas of the brain that were previously described in pain imaging studies-the pain matrix. ${ }^{30,31,33} \mathrm{~A}$ similar set of cortical and subcortical areas was activated during noxious stimulation in patients in MCS and in healthy controls. The only areas that were not significantly activated in patients in MCS were the posterior cingulate cortex and the striatum, but direct comparison of the activation of these areas between controls and patients in MCS did not show a significant difference. We cannot exclude the possibility that there is a difference in the cerebral processing of painful stimuli between patients in MCS and controls because the activation volumes were greater and more bilateral in controls than in patients in MCS; however, this might also be because of the few patients in MCS who were scanned. Finally, when patients in MCS were compared with controls no area was significantly less activated, whereas the activation of a large number of associative areas during noxious stimulation was not seen in any of the patients in PVS. ${ }^{10}$ Indeed, the patients in MCS not only had activation in the contralateral thalamus and S1, as did the patients in PVS, but also in high-order associative areas, including contralateral secondary somatosensory and posterior insular cortices, posterior parietal and dorsolateral prefrontal cortices, and anterior cingulate cortex. The whole cortical pain matrix was significantly more activated in patients in MCS than in patients in PVS when both populations were compared directly. In patients in MCS, functional connectivity between the primary somatosensory cortices and lateral frontoparietal cortices was similar to the functional connectivity in the controls. This frontoparietal network connectivity was significantly stronger in patients in MCS than in patients in PVS. These findings indicate that patients in MCS might show an elaborate and integrated level of noxious processing, which contrasts with previous findings in patients in PVS. ${ }^{10}$ The time lapse between the study in patients in PVS and the current study in patients in MCS makes unbiased comparisons difficult. However, the infrastructure (scanner, scanning protocol, and painful stimulation methodology) was matched for both studies.

Peak pain-related activation was found in the secondary somatosensory or posterior insular cortex in patients in MCS and in controls. The insular cortex is thought to be important for pain perception because it was activated in brain imaging studies on pain,,$^{31,34}$ and direct electrical stimulation of the insular cortex induces the sensation of pain in human beings. ${ }^{35}$ However, a recent PET study showed activation of the insular cortex during general anaesthesia in healthy volunteers; ${ }^{36}$ the authors interpreted these results as brain autonomic responses evoked by the noxious stimulation. In patients in MCS, however, activation of the insular cortex in response to noxious stimulation was associated with brain activity and functional connectivity in several brain areas that are involved in both the sensory and limbic aspects of pain processing. ${ }^{29-31}$ More specifically, the activation of highorder frontoparietal cortices has been repeatedly associated with the conscious perception of external stimuli in visual ${ }^{37,38}$ and somatosensory ${ }^{28,39}$ modalities. Even if the neural correlates of conscious perception and pain processing need to be fully elucidated, ${ }^{40}$ the coactivation of specialised sensory cortices and frontoparietal areas seems both necessary and sufficient to generate conscious perception. ${ }^{41}$ Although brain imaging is not a shortcut to subjectivity, we interpret the brain activation and functional connectivity patterns seen in patients in MCS as likely to show conscious perception of noxious stimuli.

Among the commonly identified cerebral areas in human neuroimaging studies, the anterior cingulate and insular cortices show particularly consistent responses during the pain.$^{42}$ Moreover, the level of activation in the anterior cingulate cortex correlates with pain intensity scores. ${ }^{30,42}$ In brain imaging studies, activation of the anterior cingulate cortex was associated with the affectivemotivational components of pain perception, ${ }^{43}$ and in the processing of stimulus intensity ${ }^{44}$ and stimulus awareness. ${ }^{28,44}$ The activation of the anterior cingulate cortex in response to noxious stimuli in patients in MCS is important because it suggests that they might also have pain affect. The impaired deactivation and functional connectivity seen in areas of the default network (ie, the posterior cingulate or precuneus and medial prefrontal cortices) ${ }^{45}$ which are thought to be involved in self-related processes, ${ }^{46}$ could show preserved but different-fromnormal perception of pain in patients in MCS.

We believe that these results should prompt the use of analgesics in patients in MCS, particularly when invasive surgery or other clinical procedures are necessary. Although pain is a first-person experience and the neural substrates of the conscious perception of pain are unknown, the extent of brain activation induced in patients in MCS in response to noxious stimulation, which was not different from that in controls, suggests that there is at least some level of pain sensory and affective perception. In our study, patients in MCS did not have significantly less activation than did the controls. However, this negative finding might be biased by reduced statistical power due to the small number of patients studied. This concern does not apply when comparing patients in MCS with those in PVS, in whom 
significant differences could be shown. We only did analyses at the group level; hence, our results do not imply that none of the patients in PVS could activate a large number of brain areas in response to noxious stimulation or that all patients in MCS do so-even if the random effects analyses we used took within-patient and between-patient variability into account. Unfortunately, the 15O-radiolabelled water PET technique does not enable us to identify reliably activation maps in individual patients. Functional MRI can tackle this problem because many more scans can be acquired per patient; these studies are currently ongoing. Our findings are relevant for the understanding of pain processing and to ethical discussions but do not provide sufficient evidence to guide the clinical management of individual patients. Variability in pain processing is expected between individuals in heterogeneous populations of patients. Although our study also stresses the need to distinguish at the bedside patients in MCS from patients in PVS, several studies have shown that misdiagnosis is common between these populations of patients. ${ }^{27}$ The evidence is not sufficient to choose not to treat potentially painful conditions in patients in PVS. Analgesic intervention in these patients is also desirable to prevent potentially damaging defensive hormonal reactions (eg, adrenal stress hormones), despite the possible absence of pain. Controlled trials that report objective outcomes, such as the absence of negative complications and survival, would enable assessment of the clinical appropriateness of analgesia in patients in PVS or MCS.

\section{Contributors}

SL, PM, AL, ML, and GM participated in the conception and design of this study. SL, MEF, CS, BL, and PL acquired the data. SL, MB, PP, CP, and $\mathrm{PM}$ analysed and interpreted the data. MB and SL drafted the manuscript. MEF, CS, PP, BL, CP, PL, AL, ML, GM, and PM revised the manuscript for intellectual content. SL, MB, PP, CP, and PM provided statistical expertise. SL, AL, PM, ML, and GM obtained funding. MEF, $\mathrm{CS}, \mathrm{BL}$, and PL provided administrative, technical, or material support, and SL, MEF, ML, GM, and PM supervised the study.

\section{Conflicts of interest}

We have no conflicts of interest.

\section{Acknowledgments}

Funding was provided by: FNRS; Reine Elisabeth Medical Foundation; University of Liège; European Commission; James S McDonnell Foundation; Mind Science Foundation; Concerted Research Action; Fondation Léon Frédéricq. We thank P Hawotte, J-L Génon, C Mesters, G Hodiaumont, and J Hodiaumont for technical assistance.

\section{References}

1 Bernat JL. Chronic disorders of consciousness. Lancet 2006 367: 1181-92

2 Giacino JT, Ashwal S, Childs N, et al. The minimally conscious state: definition and diagnostic criteria. Neurology 2002; 58: 349-53.

3 Laureys S, Boly M. What is it like to be vegetative or minimally conscious? Curr Opin Neurol 2007; 20: 609-13.

4 Teasdale G, Jennett B. Assessment of coma and impaired consciousness. A practical scale. Lancet 1974; 2: 81-84.

5 Starmark JE, Stalhammar D, Holmgren E, Rosander B. A comparison of the Glasgow coma scale and the reaction level scale (RLS85). J Neurosurg 1988; 69: 699-706.

6 Benzer A, Mitterschiffthaler G, Marosi M, et al. Prediction of nonsurvival after trauma: Innsbruck Coma Scale. Lancet 1991; 338: 977-78.
7 Sugiura K, Muraoka K, Chishiki T, Baba M. The Edinburgh-2 coma scale: a new scale for assessing impaired consciousness. Neurosurgery 1983; 12: 411-15.

8 Giacino JT, Kalmar K, Whyte J. The JFK Coma Recovery ScaleRevised: measurement characteristics and diagnostic utility. Arch Phys Med Rehabil 2004; 85: 2020-29.

9 Fins JJ, Illes J, Bernat JL, Hirsch J, Laureys S, Murphy E. Neuroimaging and disorders of consciousness: envisioning an ethical research agenda. Am J Bioeth 2008; 8: 37-46.

10 Laureys S, Faymonville ME, Peigneux P, et al. Cortical processing of noxious somatosensory stimuli in the persistent vegetative state. Neuroimage 2002; 17: 732-41.

11 Giacino JT, Kezmarsky MA, DeLuca J, Cicerone KD. Monitoring rate of recovery to predict outcome in minimally responsive patients. Arch Phys Med Rehabil 1991; 72: 897-901.

12 The Multi-Society Task Force on PVS. Medical aspects of the persistent vegetative state. N Engl J Med 1994; 330: 1499-508.

13 Giacino JT, Ashwal S, Childs N, et al. The minimally conscious state: definition and diagnostic criteria. Neurology 2002; 58: 349-53.

14 Lesser RP, Koehle R, Lueders H. Effect of stimulus intensity on short latency somatosensory evoked potentials. Electroencephalogr Clin Neurophysiol 1979; 47: 377-82.

15 Madl C, Kramer L, Domanovits H, et al. Improved outcome prediction in unconscious cardiac arrest survivors with sensory evoked potentials compared with clinical assessment. Crit Care Med 2000; 28: 721-26.

16 World Medical Association. World Medical Association declaration of Helsinki. Recommendations guiding physicians in biomedical research involving human subjects. JAMA 1997; 277: 925-26.

17 Charlton E. Ethical guidelines for pain research in humans. Committee on Ethical Issues of the International Association for the Study of Pain. Pain 1995; 63: 277-78.

18 Peigneux P, Maquet P, Meulemans T, et al. Striatum forever, despite sequence learning variability: a random effect analysis of PET data. Hum Brain Mapp 2000; 10: 179-94.

19 Boly M, Faymonville ME, Peigneux P, et al. Auditory processing in severely brain injured patients: differences between the minimally conscious state and the persistent vegetative state. Arch Neurol 2004 61: 233-38.

20 Genovese CR, Lazar NA, Nichols T. Thresholding of statistical maps in functional neuroimaging using the false discovery rate. Neuroimage 2002; 15: 870-78.

21 Owen AM, Coleman MR, Boly M, Davis MH, Laureys S, Pickard JD Detecting awareness in the vegetative state. Science 2006; 313: 1402.

22 Nichols T, Brett M, Andersson J, Wager T, Poline JB. Valid conjunction inference with the minimum statistic. Neuroimage 2005; 25 : 653-60

23 IASP. Classification of Chronic Pain: descriptions of chronic pain syndromes and definitions of pain terms. Task force on taxonomy. Seatle: IASP Press; 1994

24 Halliburton JR. Awareness during general anesthesia: new technology for an old problem. CRNA 1998; 9: 39-43.

25 Klein M. Perception of pain in the persistent vegetative state? Eur J Pain 1997; 1: 165-67.

26 Zeman A. Persistent vegetative state. Lancet 1997; 350: 795-99.

27 Schnakers C, Zasler ND. Pain assessment and management in disorders of consciousness. Curr Opin Neurol 2007; 20: 620-26.

28 Boly M, Balteau E, Schnakers C, et al. Baseline brain activity fluctuations predict somatosensory perception in humans. Proc Natl Acad Sci USA 2007; 104: 12187-92.

29 Craig AD. A new view of pain as a homeostatic emotion. Trends Neurosci 2003; 26: 303-07.

30 Coghill RC, Eisenach J. Individual differences in pain sensitivity: implications for treatment decisions. Anesthesiology 2003; 98: 1312-14.

31 Treede RD, Kenshalo DR, Gracely RH, Jones AK. The cortical representation of pain. Pain 1999; 79: 105-11.

32 Peyron R, Laurent B, Garcia-Larrea L. Functional imaging of brain responses to pain. A review and meta- analysis (2000). Neurophysiol Clin 2000; 30: 263-88.

33 Singer T, Seymour B, O'Doherty J, Kaube H, Dolan RJ, Frith CD. Empathy for pain involves the affective but not sensory components of pain. Science 2004; 303: 1157-62. 
34 Oshiro Y, Fuijita N, Tanaka H, Hirabuki N, Nakamura H, Yoshiya I. Functional mapping of pain-related activation with echo-planar MRI: significance of the SII-insular region. Neuroreport 1998; 9: 2285-89.

35 Ostrowsky K, Magnin M, Ryvlin P, Isnard J, Guenot M, Mauguiere F. Representation of pain and somatic sensation in the human insula: a study of responses to direct electrical cortical stimulation. Cereb Cortex 2002; 12: 376-85.

36 Hofbauer RK, Fiset P, Plourde G, Backman SB, Bushnell MC. Dose-dependent effects of propofol on the central processing of thermal pain. Anesthesiology 2004; 100: 386-94.

37 Rees G, Kreiman G, Koch C. Neural correlates of consciousness in humans. Nat Rev Neurosci 2002; 3: 261-70.

38 Dehaene S, Changeux JP, Naccache L, Sackur J, Sergent C. Conscious, preconscious, and subliminal processing: a testable taxonomy. Trends Cogn Sci 2006; 10: 204-11.

39 Bornhovd K, Quante M, Glauche V, Bromm B, Weiller C, Buchel C. Painful stimuli evoke different stimulus-response functions in the amygdala, prefrontal, insula and somatosensory cortex: a single-trial fMRI study. Brain 2002; 125: 1326-36.

40 Zeman A. Consciousness. Brain 2001; 124: 1263-89.
41 Rees G. Neural correlates of the contents of visual awareness in humans. Philos Trans R Soc Lond B Biol Sci 2007; 362: 877-86.

42 Derbyshire SW, Jones AK, Gyulai F, Clark S, Townsend D, Firestone LL. Pain processing during three levels of noxious stimulation produces differential patterns of central activity. Pain 1997; 73: 431-45.

43 Rainville P, Duncan GH, Price DD, Carrier B, Bushnell MC. Pain affect encoded in human anterior cingulate but not somatosensory cortex. Science 1997; 277: 968-71.

44 Buchel C, Bornhovd K, Quante M, Glauche V, Bromm B, Weiller C. Dissociable neural responses related to pain intensity, stimulus intensity, and stimulus awareness within the anterior cingulate cortex: a parametric single-trial laser functional magnetic resonance imaging study. J Neurosci 2002; 22: 970-76.

45 Boly M, Phillips C, Tshibanda L, et al. Intrinsic brain activity in altered states of consciousness: how conscious is the default mode of brain function? Ann N Y Acad Sci 2008; 1129: 119-29.

46 Boly M, Phillips C, Balteau E, et al. Consciousness and cerebral baseline activity fluctuations. Hum Brain Mapp 2008; 29: 868-74. 